\title{
GPPS-BJ-2019-225
}

\section{DRAFT: RECENT INSIGHTS INTO THE FLOW TOPOLOGY AROUND HIGHLY LOADED TANDEM VANES}

\author{
Alexander Heinrich \\ Technische Universität Berlin \\ Chair for Aero Engines \\ alexander.heinrich@ilr.tu-berlin.de \\ Berlin, Germany
}

\author{
Dieter Peitsch \\ Technische Universität Berlin \\ Chair for Aero Engines \\ dieter.peitsch@ilr.tu-berlin.de \\ Berlin, Germany
}

\begin{abstract}
A large share in the weight of aero engines is attributed to the compressor module. Weight savings are crucial for the increase of overall propulsion system efficiencies. This has led to a steady reduction of stage counts in axial compressors, implying a constant increase in stage pressure ratios. The socalled tandem blade configuration represents an innovative approach. The blades within a row are being replaced by pairs of blades placed successively in the streamwise direction, leaving a slot between the front blade's trailing edge and the rear blade's leading edge. Thus, separation from the blade suction side can be shifted towards higher incidences.

The work presented here is supported by experimental investigations which were conducted at a $2 D$ linear stator cascade at the Chair for Aero Engines at the Technische Universität Berlin. In the course of the experiments two different tandem configurations with a different Load Split (LS) setting are compared against a conventional single reference blade. All blades are designed as controlled diffusion airfoils (CDA) for a mach number Ma $=0.6$ with an elliptical leading edge and a $50^{\circ}$ turning angle. Wake flow measurements with a miniature fivehole-probe and multi-coloured oil flow visualisations are used to investigate the influence of the aerodynamic loading on the blade performance and the associated losses. This paper expands on previous findings as it includes a detailed analysis for negative incidence angles and a variation of the tangential (pitchwise) displacement of the two blade rows. The results of the oil flow visualisation complemented by wake flow measurements show the development of the secondary flow structures and the impact of varying Load Splits. In addition, the usage of multi-coloured oil flow allows a clear differentiation between origin and trajectory of different flow structures. By the use of tandem blades the losses can be, especially in the midspan region, significantly reduced. In contrast to the single reference blade, the working ranges of the tandem configurations exceed the reference stability limits even for negative inflow angles but
\end{abstract}

remain below the improvements for positive incidence angles. Furthermore the influence of the percent pitch variation on the loss production and flow guidance has been identified.

\author{
NOMENCLATURE \\ $c_{p} \quad$ static pressure rise \\ c chord length \\ f frequency \\ i incidence \\ 1 length \\ $\mathrm{p}$ pressure \\ $\mathrm{r}$ radius \\ s distance TE (FB) - LE (AB) \\ $\mathrm{t} \quad$ blade pitch \\ $\mathrm{Tu} \quad$ turbulence intensity \\ $\mathrm{x}, \mathrm{y}, \mathrm{z} \quad$ coordinates / directions

$\begin{array}{ll}\text { Greek } & \\ \alpha & \text { flow angle } \\ \beta & \text { metal angle } \\ \omega & \text { area-averaged loss coefficient }\end{array}$

\section{Subscripts \\ ax axial \\ 1 inflow condition \\ 2 exit flow condition \\ DF diffusion factor \\ DH de Haller \\ ref referred to ADP \\ S stator \\ $\mathrm{t}$ total value}

\section{Abbreviations}

2D two-dimensional 


$\begin{array}{ll}\text { 3D } & \text { three-dimensional } \\ \text { AB } & \text { Aft Blade } \\ \text { AO } & \text { Axial Overlap } \\ \text { AR } & \text { Aspect Ratio } \\ \text { CDA } & \text { Controlled Diffusion Airfoil } \\ \text { DP } & \text { Design Point } \\ \text { FB } & \text { Front Blade } \\ \text { FSO } & \text { Full Scale Output } \\ \text { LE } & \text { Leading Edge } \\ \text { LS } & \text { Load Split } \\ \text { OGV } & \text { Outlet Guide Vane } \\ \text { PS } & \text { Pressure Side } \\ \text { PP } & \text { Percent Pitch } \\ \text { SS } & \text { Suction Side } \\ \text { TE } & \text { Trailing Edge }\end{array}$

\section{Introduction and Objective}

Developing modern axial compressors for turbomachinery with the aim to increase stage pressure ratio and decrease module weight has been in the focus of research activities throughout the last decades. Conventional compressor blade designs achieve higher stage pressure ratios with an increased turning of the flow however being limited by an increased risk of separation. Therefore, modern compressor developments focus on blade row designs, which prevent separation while retaining the higher turning of the flow. Such approaches are configurations featuring tandem blades, delivering increased stage pressure ratios while avoiding separation. For tandem blades, the flow deflection is achieved by two blades positioned directly one after another. As a result the critical blade loading is split onto two blades allowing a higher pressure rise but also a more stabilised flow guidance thus reducing the risk of flow separation. The shortened chord length of each blade favors a reduced boundary layer development.

The concept of quasi passive flow control can be traced back to early works by Smith [1] or Sturm et al. [2]. In his work on high-lift aerodynamics for aircraft wings, Smith described in detail how the usage of multi-element airfoils increases lift while suppressing the risk of stall. Sturm has adapted this concept and used discrete channels to transport higher energy fluid from the pressure side to energise the suction side boundary layer. In the following, various research groups have concentrated on the optimal blade arrangement of the tandem configuration. Parameters of interest have been the chord length and the shape of both the individual blades and the pitchwise and axial position to each other. One of the main findings is that there is no universal guide for an optimum arrangement and that the latter rather depends on the field of application i.e. subsonic or transonic compressors. Subsonic applications have shown best results if the front blade has a longer chord length compared to the aft blade $[3,4,5]$. In contrast, configurations for the transonic regime perform best if the aft blade has an increased chord length compared to the front blade [6,7]. For high subsonic applications such as this study, an equal chord length ratio has proven best results and therefore serves as a baseline configuration for the current investigation $[8,9]$.

The pitchwise and axial positioning of the two blades characterises the second field of interest for tandem research. Frey and Böhle $[10,11]$ have carried out numerical and experimental tests on the influence of the tangential displacement (percent pitch). For this purpose they analysed tandem configurations with a load split of $L S=50 \%$ and two different percent pitch settings (70\% and $90 \%$ ) for the low-speed regime. They conclude in their work that a high percent pitch of $P P=90 \%$ causes fewer secondary flow losses. Moreover they also advise to use an equal chord length for both blades as this seems advantageous in order to avoid the spread of losses. Ohashi [12] was one of the first to thoroughly examine the sensitivity of the positioning of the front and the aft blade for total pressure loss production. He points out that if the pitchwise gap is too big, the beneficial and stabilising influence of the gap flow on the boundary layer development on the aft blade is lost. Müller et al. [4] as well as Schneider and Kožulović [13] have looked at the off-design performance of tandem configurations. Varying the incidence mainly affects the location of transition on the front blade. The pressure distribution and the location of the transition and the separation bubble does not change. Heinrich et al. previously could acknowledge that the front blade absorbs the incidence changes $[14,15]$. In addition to the off-design examinations they demonstrated that if the pitchwise gap is chosen too large, the front and aft blade perform as two single blades. An optimum configuration for the design point was found at percent pitch of $P P=91 \%$. For an incidence variation of $i=+5 \mathrm{deg}$ the optimum configuration could be found for a percent pitch of $P P=95 \%$. This shift towards to a smaller gap size for high incidence angles was also confirmed by Schneider [13]. An increase in inflow angle further accelerates the flow, drawing more fluid through the gap and therefore maintains the positive tandem effect at high incidence angles.

This paper expands on previous findings as it includes a detailed analysis for negative incidence angles and a variation of the tangential (pitchwise) displacement of the two blade rows. Thus for the first time, the performance characteristics for high turning tandem blades over the entire operating range are presented at a glance and allow a complete evaluation of the flow characteristics. 


\section{Blade Design}

The reference blades are designed as controlled diffusion airfoils (CDA) with an elliptical leading edge. The blade height is constrained by the width of the test section and set to $h=63 \mathrm{~mm}$. The length of the test section which is $l_{T S}=256 \mathrm{~mm}$ allows to insert up to nine blades which results in eight blade passages (depending on blade pitch) and account for a good periodicity. All blades can be replaced independently. The entire test section can be rotated to allow for $\mathrm{a} \pm 10^{\circ}$ incidence variation.

The nomenclature for the corresponding tandem configurations is shown in Fig. 1.

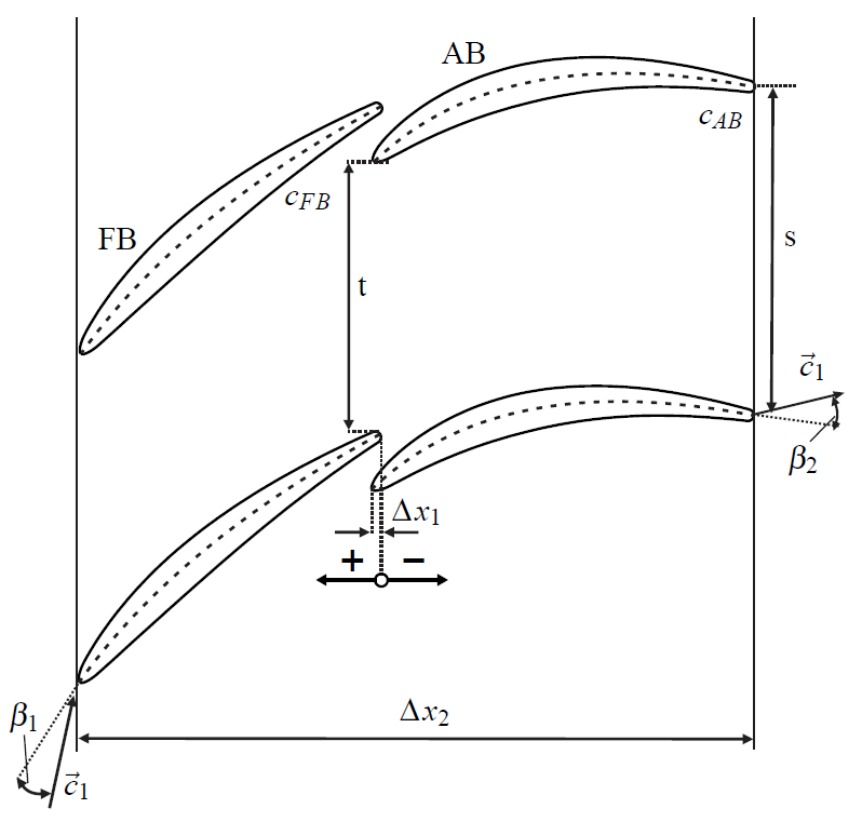

FIGURE 1: Tandem blade geometric parameters

Key parameters when designing tandem blades are the load split (LS), the axial overlap (AO) and the tangential displacement (Percent Pitch - PP).

The axial overlap $\left(A O=\Delta x_{1} / \Delta x_{2}\right)$ and tangential displacement $(P P=t / s)$ define geometric parameters whereas the load split basically characterises the work share between the front (FB) and the aft blade (AB).

As stated before, relevant literature suggests a load split of $L S=50 \%[8,16]$. The load split can be defined in many ways. For this reason, and the missing of explicit differentiation in the available literature, this paper has examined two variations - namely the definiton according to the DE HALLER number $\left(\mathrm{LS}_{\mathrm{DH}}\right)$ and the diffusion factor $\left(\mathrm{LS}_{\mathrm{DF}}\right)$ of LIEBLEIN [17].

$$
\mathrm{LS}_{\mathrm{DH}}=\frac{\mathrm{DH}_{\mathrm{FB}}}{\mathrm{DH}_{\mathrm{FB}}+\mathrm{DH}_{\mathrm{AB}}}=0.5
$$

$$
\mathrm{LS}_{\mathrm{DF}}=\frac{\mathrm{DF}_{\mathrm{FB}}}{\mathrm{DF}_{\mathrm{FB}}+\mathrm{DF}_{\mathrm{AB}}}=0.5
$$

In order to fulfill these two definitions, the individual turning of the respective front and aft blade had to be adjusted while keeping the overall turning constant. For this reason, the front blade of the $\mathrm{LS}_{\mathrm{DF}}$ tandem (case \#2) features a higher turning to meet the load requirements compared to the $\mathrm{LS}_{\mathrm{DH}}$ tandem (case \#1).

All blades are designed for an inflow Mach number of $M a=0.6$ and a nominal flow turning of $\beta=50 \mathrm{deg}$ at design point. Furthermore the working range of all configurations was set to $\Delta \beta= \pm 5 \mathrm{deg}$ during the design process which resulted in an adjustment of the blade pitch. This was necessary to achieve comparable experimental boundary conditions. The main geometric parameters of the tandem vanes are summarised in table 1.

The axial overlap was set $A O=0.01$ and is a direct result of the manufacturing process of the tandem vanes as it was intended to allow for a variation of the tangential displacement. By tangentially repositioning the aft blade, the percent pitch could be altered from the design point $P P_{D P}=91 \%$. Thus by inserting discrete spacers, a total of four different configurations $(\mathrm{PP}=85 \%, 88 \%, 91 \%$ and $95 \%$ ), representing a common range found in literature, could be analysed.

The chord length of the reference blade was $c_{r e f}=63 \mathrm{~mm}$ with an aspect ratio of $A R=1$ and a pitch-to-chord ratio of $s / c=0.45$. In order to maintain the geometric similarity to the reference blade, the chord length of both the front and the aft blades of the tandem vanes was set to $c_{\text {tandem }}=31.5 \mathrm{~mm}$ and the thickness-to-chord ratio of $t / c=0.1$.

\section{Experimental and Measurement Setup}

The experiments have been carried out at the 2D linear high-speed compressor cascade of the Chair for Aero Engines at Technische Universität Berlin. The high-speed cascade is fed by three radial compressors with a maximum combined

TABLE 1: Blade geometric parameters

\begin{tabular}{lcccccc}
\hline Tandem & $\beta_{1}\left[^{\circ}\right]$ & $\beta_{2}\left[^{\circ}\right]$ & $\Delta \beta\left[^{\circ}\right]$ & $\mathrm{s} / \mathrm{c}$ & $\mathrm{LS}_{D H}$ & $\mathrm{LS}_{D F}$ \\
\hline$\# 1: \mathrm{FB}$ & 50.00 & 37.62 & 12.38 & 0.51 & 0.50 & 0.42 \\
$\# 1: \mathrm{AB}$ & 37.62 & 0.00 & 37.62 & 0.51 & 0.50 & 0.42 \\
$\# 2: \mathrm{FB}$ & 50.00 & 33.45 & 16.55 & 0.45 & 0.47 & 0.50 \\
$\# 2: \mathrm{AB}$ & 33.45 & 0.00 & 33.45 & 0.45 & 0.47 & 0.50 \\
\hline
\end{tabular}


power of $1 \mathrm{MW}$. Before entering the test section the flow passes a settling chamber equipped with different filters and flow straighteners followed by a nozzle. Turbulence intensity at the nozzle outlet is $T u \leq 1 \%$. The test facility has been previously used and validated by Tiedemann et al. and their work is recommended for further information $[18,19]$.

Pressure and temperature tappings in the settling chamber are used to record the total pressure $p_{t}$ and temperature $T_{t}$. Static pressure tappings half a chord length of the blade leading edges are used to monitor periodic inflow conditions and determine the inflow Mach number. The incoming boundary layer thickness has been determined one chord length upstream using the hot-wire-measurement technique and accounts to $\delta_{99}=5.5 \mathrm{~mm}$. Figure 2 shows the $2 \mathrm{D}$ linear stator cascade at which the experiments have been carried out.

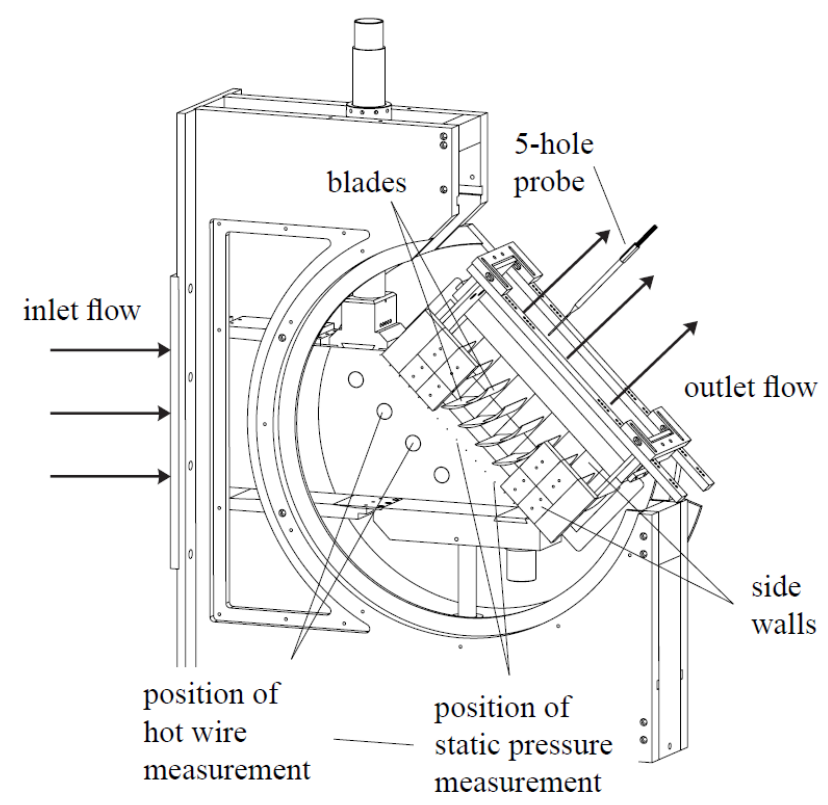

FIGURE 2: Cascade wind tunnel and access locations

Wake flow measurements have been carried out to capture the cascade characteristics. The measurement domain was located half a chord length behind the trailing edge which allowed to still record the specific wake topologies. A miniature five-hole-probe was used in order to keep the influence on the measurement itself sufficiently small. A $3 \mathrm{~mm}$ offset to the endwall was necessary due to size of the five-hole-probe. Figure 3 shows the respective measurement domains.

In addition, oil flow visualisations are carried out and aid the understanding of the underlying flow phenomena. The oil emulsion is composed of liquid paraffin oil which is mixed with coloured pigments. Using differently coloured mixtures for the pressure and suction side as well as the endwall allows to not only capture the surface streaklines but also to trace them back to their respective origin. The analysis of the flow pattern is done according to Maltby [20].

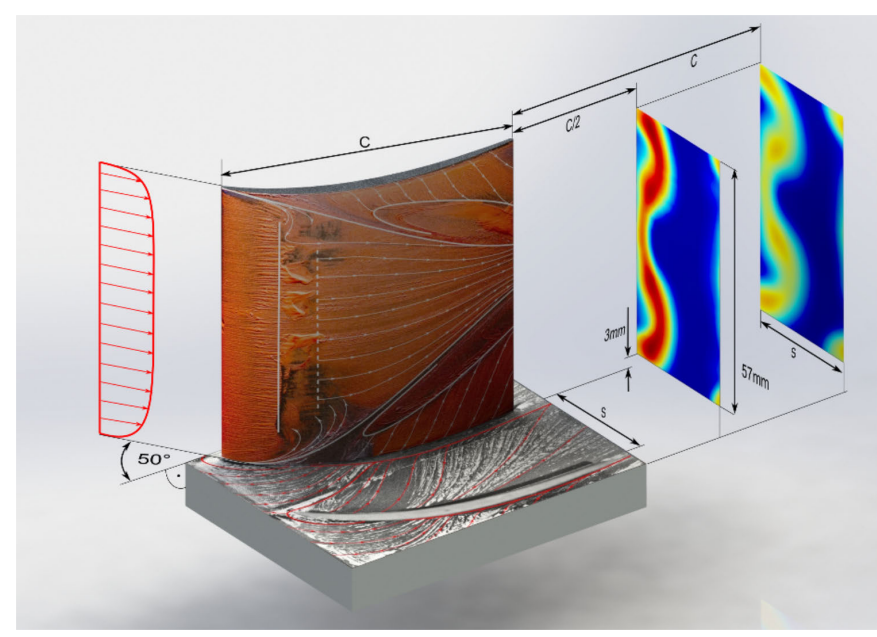

FIGURE 3: Measurement domains

Data acquisition has been done using a Dewetron 50 PCI measurement system. The differential pressure sensors (First Sensor HDO series) had a pressure range of $0-200$ mbar with an uncertainty of $\pm 0.5 \%$ based on full scale output (FSO). For time averaged property reading, the measurement time was set to $10 \mathrm{~s}$ and the sampling frequency to $f=10 \mathrm{kHz}$.

Relevant parameters such as the total pressure loss $\omega$ (Eq. 3), the static pressure rise $c_{p}$ (Eq. 4) and the flow turning $\Delta \beta$ (Eq. 5) are used to evaluate the respective cascade characteristics. The total pressure loss is defined as

$$
\omega=\frac{p_{t 1}-p_{t 2}}{p_{t 1}-p_{1}}
$$

The static pressure rise $c_{p}$ can be calculated using

$$
c_{p}=\frac{p_{2}-p_{1}}{p_{t 1}-p_{1}} .
$$

The flow turning $\Delta \beta$ is the difference of the inflow and exit flow angle and denoted as

$$
\Delta \beta=\beta_{1}-\beta_{2}
$$

\section{Results}

Oil flow visualisations of the suction side of the single reference blade at an off-design angle of $5 \mathrm{deg}$ indicated a flow detachment. Figure 4 (right side) shows that the flow is entirely detached at the trailing edge (TE) and spans across the full blade height. Significant to note are also the areas of reversed flow which unite in midspan.

Accompanying wake flow area measurements (cf. Fig. 5) have proven the assumption of a steep total pressure loss increase and also show that the wake flow signature is not of symmetrical nature any more. 

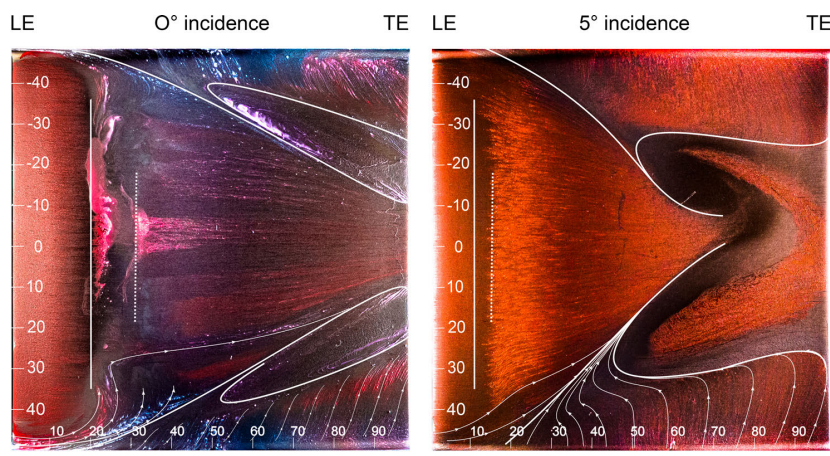

FIGURE 4: Oil flow visualisation of the suction side of the reference blade at 0 and $5 \mathrm{deg}$ incidence

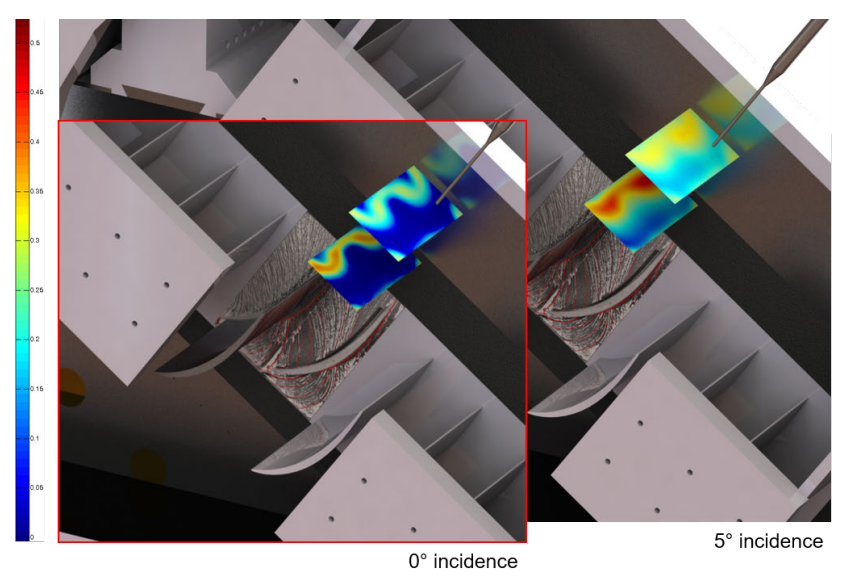

FIGURE 5: Flow topology of reference blade at 0 and 5 deg incidence

In contrast, the oil flow visualisations of the suction side of the tandem blades $\left(L S_{D H}, P P=91 \%\right.$ - design percent pitch) for $0 \mathrm{deg}$ (cf. Fig. 6 left) and 5 deg incidence (cf. Fig. 6 right) show that even at large off-design angles the flow is attached. In fact, the aft blade seems unaffected by the incidence change with no increased constriction of the flow towards midspan or an increased corner separation development. The incidence change has been completely absorbed by the front by the front blades.

The qualitative wake flow area measurements for the tandem blades (cf. Figure 7) clearly show that the distinct tandem wake topology is still present at the $5 \mathrm{deg}$ off-design angle. Clearly visible is the area of undisturbed flow in the midspan region.

Wake flow measurements for the single reference blade and both tandem configurations $L S_{D H}$ and $L S_{D F}$ at the design percent pitch (PP) have been carried out for an entire operating range from $\Delta \beta=-4 \longleftrightarrow 5 \mathrm{deg}$. The results are summarised in Figure 8 and show the mass-averaged cascade characteristics for total pressure loss $\omega$ and pressure rise $c_{p}$ for different turning angles $\beta$. By the use of tandem blades the total pressure losses could be reduced over the entire

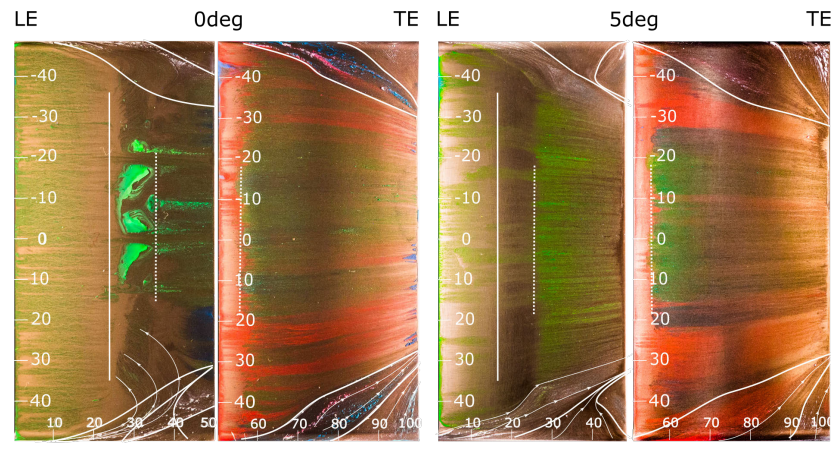

FIGURE 6: Oil flow visualisation of the suction side of the $L S_{D H}$ tandem blade at 0 and $5 \mathrm{deg}$ incidence

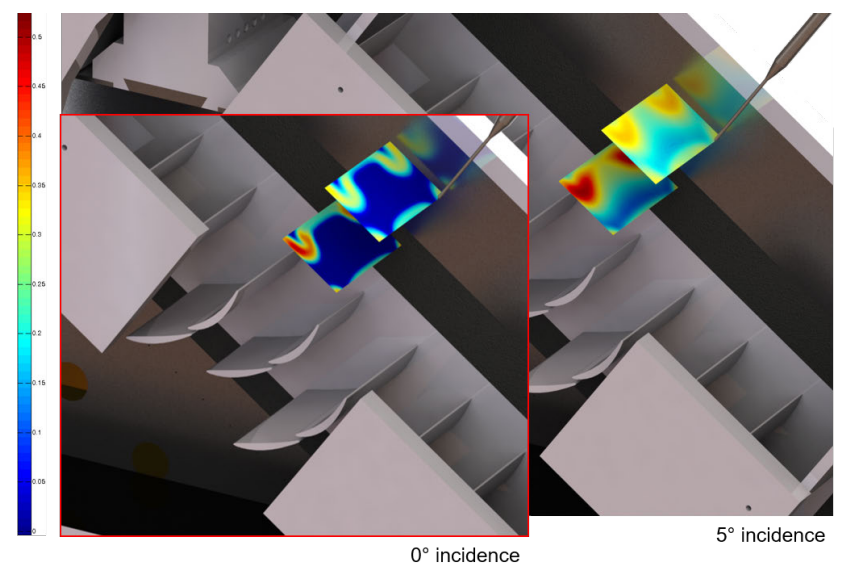

FIGURE 7: Flow topology of tandem blade at 0 and 5 deg incidence

working range. For the nominal inflow of $\beta=50 \pm 2 \mathrm{deg}$ both tandem configurations show similar values. For larger positive incidence angles, the $L S_{D F}$ tandem design according to Lieblein (case \#2) produces higher losses. These higher losses can be traced back to the more aggressive turning of the front blade (cf. Table 1) which showed a +4 deg higher turning of the front blade compared to the $L S_{D H}$ tandem (case \#1).

As a result, the higher blade loading spurs a stronger secondary flow development due to the earlier onset of the corner vortices and thus a longer remaining chord length. For the negative incidence change, the two tandem configurations show an opposite trend. The stronger turning of the front blade of the $L S_{D F}$ design now positively counteracts the negative incidence change. Overall, the total pressure loss development is of similar character, but differs strongly for positive incidence angles which increases the stability limit.

The pressure rise is also evaluated across the operating range and shown in Figure 8. It could be increased for positive incidences by $10 \%$ compared to the reference blade. Nevertheless is also does start to collapse for higher positive incidence angles (as well as the reference blade), but remains on a higher overall level. On the negative branch, the values drop below those for the reference blade. The $L S_{D} F$ tandem design overally achieves higher values than the $L S_{D H}$ design and can even absorb some of the rapid decrease. 


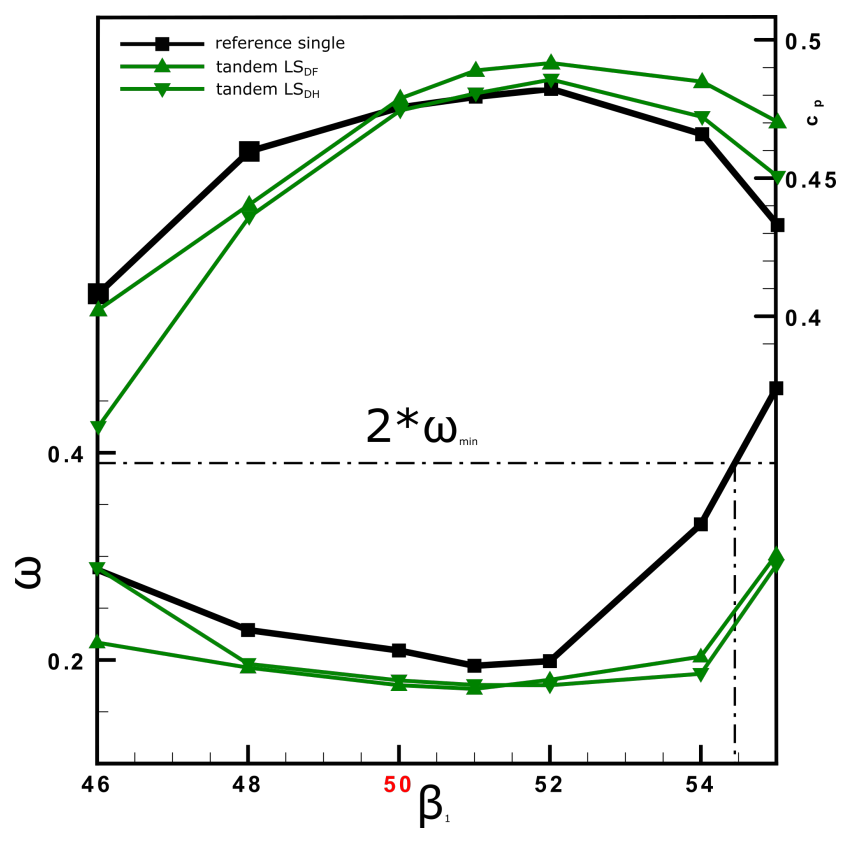

FIGURE 8: Mass-averaged cascade characteristics for reference and tandem blade configurations

As previously shown by Sanger [21] and also Heinrich et al. $[14,15]$ the positioning of the front and the aft blade and in particular the percent pitch variation has a strong influence on the flow topology. Previous work has analysed the flow topology with the aid of oil flow visualisation and shown in particular the influence of the gap flow on the secondary flow development on the aft blade. It could be concluded that the front and aft blade behave as two separate blades with increased losses if the gap is chosen too large. On the other hand it could be shown, that a minimum gap flow is needed in order to suppress the secondary flow development on the aft blade.

Figure 9 now summarises those qualitative findings in terms of total pressure loss values and sets them in constrast to each other. There is a general trend visible which is that for large incidence angles a $50 \%$ load split according to DE HALLER is favourable in terms lower total pressure losses. On the negative branch, the $L S_{D F}$ design according LIEBLEIN shows overall lower losses for all percent pitch variations. Further visible is that the optimum percent pitch setting changes over the operating range. A tangential displacement of $P P=$ $95 \%$ produces lowest losses at high positive incidence angles, but is accountable for highest values on the negative branch. The $P P=85-88 \%$ settings seem to be the favourable configurations.

\section{Conclusions}

Two sets of tandem blades with different load splits and varying tangential displacement have been experimentally compared to a single reference blade. Wake flow measurements and oil flow visualisation have been used to analyse the

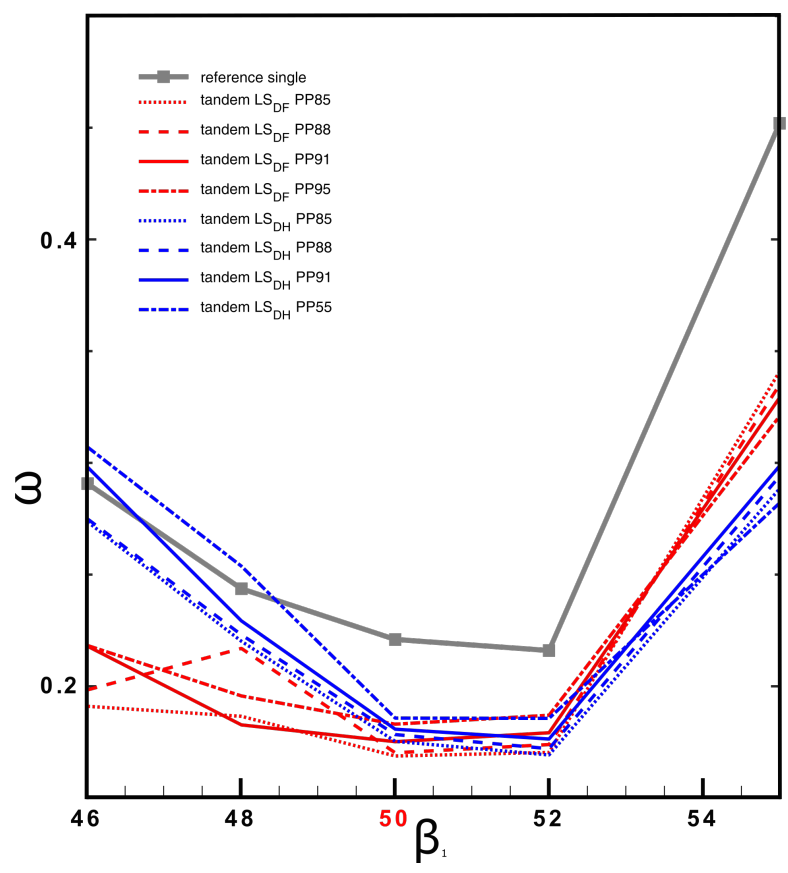

FIGURE 9: Mass-averaged cascade characteristics for reference and tandem blade configurations

blade configuration with respect to total pressure losses, pressure rise, flow guidance and suppression of flow separation.

The results of the oil flow visualisation complemented by wake flow measurements show the development of the secondary flow structures and the impact of varying Load Splits. In addition, the usage of multi-coloured oil flow allows a clear differentiation between origin and trajectory of different flow structures. By the use of tandem blades the losses can be, especially in the midspan region, significantly reduced.

In contrast to the single reference blade, the working ranges of the tandem configurations exceed the reference stability limits even for negative inflow angles but remain below the improvements for positive incidence angles. Furthermore the influence of the percent pitch variation on the loss production and flow guidance has been identified.

The following remarks represent a summary of the key findings.

1. Using tandem blades the resulting pressure losses compared to the single reference blade could be reduced while realising a higher pressure rise across the stage.

2. The working range of tandem configurations well exceeds the reference blade's stability limit.

3. The oil flow visualisations as well as the wake flow measurements show that losses in the midspan area can be clearly reduced.

4. Due to the shortened chord-length, the development of the corner vortices on each of the tandem blades is interrupted and the vortex cores remain close the sidewall.

5. However there are now two sets of corner vortices on each 
side, which, as a result of their interaction, generates areas of higher absolute losses on both sides of the endwall.

6. The analysis of the different blade loadings shows, that the load share has to be carefully chosen. The stronger turning of the front blade of the LIEBLEIN configuration generates higher losses which cannot be accumulated by the aft blade.

\section{ACKNOWLEDGMENT}

The research for this work has been carried out within the framework of the programme to support research and development in small and medium-sized enterprises (SMEs) of the Federal Ministry for Economic Affairs and Energy (BMWi) through the German Federation of Industrial Research Associations (Arbeitsgemeinschaft industrieller Forschungsvereinigungen (AiF) e.V.). It is the scientific result of a research project outlined by the Research Association for Combustion Engines e.V. (Forschungsvereinigung Verbrennungskraftmaschinen e.V. (FVV, Frankfurt)) and conducted by the Institute of Aeronautics and Astronautics (ILR) of the Technische Universität Berlin. The work was funded by the Federal Ministry for Economic Affairs and Energy (BMWi).

\section{REFERENCES}

[1] Smith, A., 1975. "High-Lift Aerodynamics". Journal of Aircraft, 12(6), pp. $501-530$.

[2] Sturm, W., Scheugenpflug, H., and Fottner, L., 1992. "Performance Improvements of Compressor Cascades by Controlling the Profile and Sidewall Boundary Layers". Journal of Turbomachinery, 114(3), pp. 477-486.

[3] Hoeger, M., Baier, R.-D., Fischer, S., and Neudorfer, J., 2011. "High Turning Compressor Tandem Cascade for High Subsonic Flows, Part 1: Aerodynamic Design". In 47th AIAA/ASME/SAE/ASEE Joint Propulsion Conference \& Exhibit, no. AIAA 2011-5601, AIAA, American Institute of Aeronautics and Astronautics.

[4] Mueller, L., Kozulovic, D., Wulff, D., Fischer, S., and Stark, U., 2011. "High Turning Compressor Tandem Cascade for High Subsonic Flows - Part 2: Numerical and Experimental Investigations". In 47th AIAA/ASME/SAE/ASEE Joint Propulsion Conference \& Exhibit, no. AIAA 2011-5602, AIAA, American Institute of Aeronautics and Astronautics.

[5] Hergt, A., and Siller, U., 2016. "About Subsonic Compressor Tandem Aerodynamics - A Fundamental Study". In ISROMAC International Symposium on Transport Phenomena and Dynamics of Rotating Machinery.

[6] Hergt, A., and Siller, U., 2015. "About Transonic Compressor Tandem Design: A Principle Study”. In Volume 2A: Turbomachinery, no. GT2015-42115, ASME.

[7] Hergt, A., Grund, S., Klinner, J., Steinert, W., Beversdorff, M., and Siller, U., 2019. "Some Aspects of Transonic Compressor Tandem Design”. Journal of Turbomachinery (accepted), mar.

[8] McGLUMPHY, J., and NG, W.-F., 2007. "Overview of a
Simple Design Rule for Subsonic Tandem-Airfoil AxialFlow Compressor Blades in 2-D”. In Proceedings of Student Research Conference, Vol. 9, Virginia Space Grant Consortium, p. 8.

[9] McGlumphy, J., Ng, W.-F., Wellborn, S. R., and Kempf, S., 2010. "3D Numerical Investigation of Tandem Airfoils for a Core Compressor Rotor". Journal of Turbomachinery, 132(3), July, p. 31009.

[10] Frey, T., and Böhle, M., 2013. "Three-Dimensioank near Wall Flow Phenomena of a Tandem Cascade". In Proceedings of 10th European Conference on Turbomachinery Fluiddynamics \& Thermodynamics, pp. 1-12.

[11] Böhle, M., and Frey, T., 2014. "Numerical and experimental investigations of the three-dimensional-flow structure of tandem cascades in the sidewall region". Journal of Fluids Engineering, 136(7), may, p. 071102.

[12] Ohashi, H., 1959. "Theoretische und experimentelle Untersuchungen an Tandem-Pumpengittern starker Umlenkung”. Ingenieur-Archiv, 27(4), pp. 201-226.

[13] Schneider, T., and Kožulović, D., 2013. "Flow Characteristics of Axial Compressor Tandem Cascades at Large Off-design Incidence Angles". In ASME Turbo Expo 2013: Turbine Technical Conference and Exposition, no. GT2013-94708, ASME, American Society of Mechanical Engineers.

[14] Heinrich, A., Tiedemann, C., and Peitsch, D., 2015. "Experimental Investigations of Secondary Flow Development Around Tandem Vanes in a 2D Linear Stator Compressor Cascade". In Proceedings of 11th European Conference on Turbomachinery Fluiddynamics \& Thermodynamics, no. ETC2015-237.

[15] Heinrich, A., Tiedemann, C., and Peitsch, D., 2017. "Experimental Investigations of the Aerodynamics of Highly Loaded Tandem Vanes in a High-Speed Stator Cascade". In Proceedings of ASME Turbo Expo 2017: Turbomachinery Technical Conference and Exposition, no. GT2017-63235, ASME.

[16] McGlumphy, J., 2008. "Numerical Investigation of Subsonic Axial-Flow Tandem Airfoils for a Core Compressor Rotor". PhD thesis, Virginia Polytechnic Institute and State University, Jan.

[17] Lieblein, S., and Roudebush, W. H., 1956. Theoretical loss relations for low-speed two-dimensional-cascade flow. techreport NACA-TN-3662, Lewis Flight Propulsion Laboratory, Cleveland, Ohio, USA.

[18] Tiedemann, C., Heinrich, A., and Peitsch, D., 2012. "A New Linear High Speed Compressor Stator Cascade for Active Flow Control Investigations". In 6th AIAA Flow Control Conference, no. AIAA 2012-3251, AIAA, American Institute of Aeronautics and Astronautics.

[19] Tiedemann, C., Peitsch, D., Steinberg, S., and King, R., 2012. "Identifikation einer Regelgröße zur aktiven Strömungskontrolle an einer linearen Verdichterkaskade im kompressiblen Machzahlbereich”. In Deutscher Luftund Raumfahrtkongress 2012, DGLR.

[20] Maltby, R. L., 1962. Flow visualization in wind tunnels using indicators. No. AGARD-AG-70 in Agardograph 
70. N.A.T.O. Adv. Group for Aeronaut. Res \& Dev, Paris, Apr.

[21] Sanger, N. L., 1971. ANALYTICAL STUDY OF THE EFFECTS OF GEOMETRIC CHANGES ON THE FLOW CHARACTERISTICS OF TANDEM-BLADED COMPRESSOR STATORS. Tech. rep., NATIONAL AERONAUTICS AND SPACE ADMINISTRATION WASHINGTON, DC. 